\title{
INVESTIGATION OF THE OPTICAL PROPERTIES OF CHITOSAN AND RICE STARCH BLENDS, AS A FILLER IN PAPER OR AS A FILM FOR PACKAGING APPLICATIONS
}

\author{
Urška Vrabič Brodnjak ${ }^{1}$ (D), Dimitrina Todorova ${ }^{2}$ (i) \\ ${ }^{1}$ University of Ljubljana, Faculty of Natural Sciences and engineering, Department of Textiles, \\ Graphic Arts and Design, Ljubljana, Slovenia \\ ${ }^{2}$ University of Chemical Technology and Metallurgy, Department of Pulp, Paper and \\ Printing Art, Sofia, Bulgaria
}

\begin{abstract}
Bio based materials fall under the broad category of bio-products or bio-based products, which includes materials, chemicals and energy derived from renewable biological resources. This research shows the preparation of both, paper sheets with blend fillers of chitosan and rice starch and chitosan and rice starch films, which could be used as packaging material for a variety of applications. In this research, we used a blend mixture, different concentrations of chitosan and rice starch both in paper production and in films to investigate the optical properties of the obtained materials with a combination of ultrasonic treatment during the film formation. The research showed that the optical properties of the obtained packaging materials improved. It also showed that blend fillers of chitosan and rice starch are effective paper fillers in the preparation of cellulose mixture for bio based packaging materials and the optical properties are with slight changes. The investigation on the optical properties of the obtained paper samples during accelerated thermal showed that the ageing of paper with addition of chitosan and chitosan and rice starch blends had the same behaviour through the 72 hours of ageing. The ultrasonic treatment of the films improved transparency. The surface at untreated blend film was more uneven compared to chitosan and rice starch films, which improved after the treatment.
\end{abstract}

Key words: bio based polymers, fillers, packaging, properties, analysis.

\section{INTRODUCTION}

In the last decade, interest in biodegradable polymers has been focused on packaging materials derived from renewable resources (Ten and Vermerris, 2013). Such polymers include chitosan and starch, which have already been produced in many applications (Puvvada et al, 2012; Mendes et al, 2016; Aghazadeh et al, 2018). Consequently, wood-fibre paper is a rather heterogeneous material containing cellulose fibres, consisting of lignin, hemicellulose and other substances such as ash, dust, etc. Cellulose is a semicrystalline polysaccharide composed of cyclically recurring monomer units of glucose, which form long parallel linear chains of cellulose. The linear macromolecules of cellulose form strong crystallites and weak non-crystalline (amorphous) domains through hydrogen bonds formed between the lateral hydrogen atoms of one chain and the hydroxyl groups of the glucose units of the adjacent chain (lolovich, 2016; Li et al, 2015; Lindh et al, 2016). They also occur between hydroxyl groups of adjacent glucose units within the macromolecule. Due to transverse hydrogen bonds between macromolecules of glucose units, the macromolecules are close together. This prevents the interaction of glucose units with water, which identifies cellulose as partially crystalline, as already mentioned. On a structural level, paper can be regarded as a dense network of cellulose fibres consisting of cellulose microfibrils embedded in a matrix of lignin and hemicellulose. Chitosan is a polymer which is used as an additive in many areas, not only in paper production (Khalil et al, 2016). Its chemical structure is very similar to the glucose unit of cellulose, but the amino group is located at the site of the hydroxyl group. Chitosan acts as an antibacterial agent and, as a water barrier, influences the water resistance of the paper, which can be found in a number of literary sources (Maitra and Singh, 2018; Tang et al, 2016; Amirabad et al, 2018; Jung et al, 2018; Zarayneh et al, 2018). It is very poorly soluble in water (Flores-Hernández et al, 2018; López-Mata, 2018; Sabbah et al, 2019). Namely, it achieves water resistance by combining its amino groups with hydroxyl groups of cellulose, thereby forming strong hydrogen bonds that prevent water from binding to the cellulose molecule (Zarayneh et al, 2018; Phan et al, 2019).

Rice starch also consists of glucose units, which, in contrast to cellulose and chitosan, are linked together to form a more branched structure. Most types of starch contain two types of glucose polymers: a linear chain molecule, i.e. amylase, and a branched polymer glucose, i.e. amylopectin (Bourtoom and Chinnan, 
2008; Woggum et al, 2015; Thakur et al, 2016). In general, the positive cationic starch molecules are linked to the negatively charged cellulose molecules, which can increase the strength of the paper. The use in paper should be handled with care, especially with the higher quantities; the elasticity can be negatively affected (Bourtoom and Chinnan, 2009; Ashwar et al, 2015; Romani et al, 2017). Rice starch is insoluble in cold water and becomes water-soluble when heated (Mathew et al, 2018). In the manufacture of paper, rice starch has been used as an additional component in films that form blends with other biopolymers (Vrabič Brodnjak, 2017). In general, rice starch is used as a binder for various coatings (Bourtoom and Chinnan, 2008; Ashwar et al, 2015; Shah, 2016; Ogunsona, 2018; Hoyos-Leyva, 2018). The mechanical properties of paper are primarily determined by the cellulose fiber properties, the fire network structure and the properties of the added non-fibrous materials and in some cases also by the adhesive forces between the individual fibers, microfibres and molecular chains. This research also shows the preparation, characterisation and ultrasonic treatment of the blend chitosan-rice starch films. The aim of the research was also to improve the mechanical, moisture and optical properties of chitosan, rice starch and composite chitosan-rice starch film using ultrasonic treatment.

The production of improved paper with improved tensile properties using biodegradable macromolecules is quite limited. Therefore, the primary objective of this research was to determine the influence of different paper fillers, i.e. chitosan and rice starch, together with their different concentrations, on the optical, moisture and mechanical properties and thermal ageing. Optical, mechanical and surface properties were analysed. The result of this research is paper with added chitosan and rice starch, which can be used to produce packaging materials for different purposes.

\section{MATERIALS AND METHODS}

\subsection{Materials}

In this research paper, filler solutions with different amounts of chitosan and rice starch were applied into paper pulp suspension and then the paper was produced as described in the previous research (Brodnjak and Todorova, 2017). At the same time chitosan and rice starch films as packaging material has been manufactured separately and properties were determined.

Chitosan, with the molecular weight lower than $20 \mathrm{kDa}$ and deacetylation degree higher than 85\%, was purchased from Sigma Aldrich (Austria). Acetic acid (99\%) was purchased from Sigma Aldrich (Austria). Rice starch was obtained from Farmalabor Srl (Italy) and had 14\% of moisture content, 1\% of proteins and $0.6 \%$ of ashes. Modified cationic polyacrylamide was delivered by Kemira, Finland and is with Molecular Weight of $11.10^{6} \mathrm{~g} / \mathrm{mol}$, Charge Density of $1,05 \mathrm{meq} / \mathrm{g}$, Viscosity (Brookfield) $700 \mathrm{cP}\left(0,5 \%, 25^{\circ} \mathrm{C}\right)$ and Conductivity $66,6 \mu \mathrm{S}_{(0,5 \%)}$. Glycerol, obtained from Sigma Aldrich (Austria), was also used as a plasticiser at films.

\subsubsection{Paper}

Paper suspensions were prepared using 6 combinations of pulp suspensions, bio polymers (chitosan and rice starch) and retention additive.

The procedure of mixing pulp and other additives was as followed: firstly $23,5 \mathrm{~g}$ o.d.f. were stirred in tap water $(2000 \mathrm{ml})$, then the chitosan and rice starch were added. The mixing proceeded and after that the retention additive was added.

The preparation was followed with mixtures:

1. Only pulp (P)

2. Pulp and $0,05 \%$ retention additive (PR)

3. Pulp, $5 \%$ chitosan, $0,05 \%$ retention additive $(5 \% \mathrm{CH})$

4. Pulp, $5 \%$ of rice starch and chitosan, $0,05 \%$ retention additive ( $5 \% \mathrm{CHR})$

5. Pulp, $7.5 \%$ chitosan, $0,05 \%$ retention additive $(7.5 \% \mathrm{CH})$

6. Pulp, $7.5 \%$ of rice starch and chitosan, $0,05 \%$ retention additive $(7.5 \% \mathrm{CHR})$

\subsubsection{Films}

The rice starch dispersion was prepared by dissolving $2 \mathrm{~g}$ of rice starch in $100 \mathrm{ml}$ of distilled water and glycerol $(40 \% \mathrm{w} / \mathrm{w})$ was added as a plasticiser. The solution was mixed until it gelatinised $\left(85^{\circ} \mathrm{C}\right.$ for 20 $\min$ ) and then cooled to room temperature. 
The chitosan solution was prepared by dissolving $2 \mathrm{~g}$ of chitosan in $100 \mathrm{ml}(2 \% \mathrm{w} / \mathrm{w})$ malic acid and glycerol $(40 \% \mathrm{w} / \mathrm{w})$ was added as a plasticiser. The solution was mixed at $90{ }^{\circ} \mathrm{C}$ for 5 minutes until chitosan was not dispersed and after that cooled to room temperature. Before cooling down, the film solution was filtered through a polyester screen (mesh no. 140 with mesh opening $160 \mu \mathrm{m}$ ) with aspiration to remove small lumps in the solution.

The rice starch-chitosan film was prepared by mixing $100 \mathrm{ml}$ of $2 \%$ rice starch solution with $100 \mathrm{ml}$ of $2 \%$ chitosan solution. After that, $40 \%$ of glycerol as a plasticiser (w/w; of total solid weight in solution) was added into the mixed solution. The total solution for blend film was mixed at $800 \mathrm{rpm}$ for 5 minutes at room temperature and then filtered through a polyester screen with the same mesh opening as at the chitosan solution. The aspiration was performed in order to remove small lumps in the solution.

After the aspiration, the solutions (for chitosan, rice starch film and blend film) were placed into an ultrasonic bath (Asonic, Ultrasonic bath), using constant $35 \mathrm{kHz}$ frequency for 15 minutes.

After aspiration and treatment, the mixtures (untreated and treated) were poured onto Petri dishes (50 $\mathrm{ml}$ ), spread thinly and evenly and dried at $55{ }^{\circ} \mathrm{C}$ for 10 hours. After the films had been peeled off the trays, they were cooled at room temperature $\left(23^{\circ} \mathrm{C} ; 55 \% \mathrm{RH}\right)$. $\mathrm{RH}$ For further investigations the films were stored in desiccators at $60 \%$.

\subsection{Methods}

\subsubsection{Grammage, density, specific surface, thickness}

Grammage of all samples was determined in accordance with the ISO 536 standard. Density and specific surface volume were calculated form grammage and thickness, as described in the standard method ISO 534.

\subsubsection{Colour of the films}

The film colour was determined using CIE colorimeter $X$-rite. The CIE Lab scale was used to determine $L^{*}$, $a^{*}$ and $b^{*}$ colour values. A standard plate was used as the standard $\left(L^{*}=92.82, a^{*}=-1.24, b^{*}=0.5\right)$. Six measurements for each specimen at different locations on samples were made. Before the colour measurements, the samples were conditioned at $55 \% \mathrm{RH}$ and $25 \pm 2{ }^{\circ} \mathrm{C}$ for $72 \mathrm{~h}$.

\subsubsection{Smoothness and air permeability}

Smoothness and air permeability were determined according to standard TAPPI T460 and ISO 8791-2.

\subsubsection{Surface (SEM)}

The SEM micrographs of paper and film surfaces were taken with a scanning electron microscope (JSM$6060 \mathrm{LV})$. The instrument operated at $10 \mathrm{kV}$ and at the magnification 1000x.

\subsubsection{Printing quality of papers}

\section{a) Colour values and gloss}

The colour of sample papers was determined with a CIE colorimeter X-rite. The CIE Lab scale was used to determine the $L^{*}, a^{*}$ and $b^{*}$ colour values. The plate was used as a standard $\left(L^{*}=92.82, a^{*}=-1.24, b^{*}=\right.$ 0.5). For each sample, ten measurements were made at different locations on the surface. Before the colour measurements, the samples were conditioned at $60 \% \mathrm{RH}$ and $27 \pm 2{ }^{\circ} \mathrm{C}$ for $72 \mathrm{~h}$.

Gloss was determined as the specularly and diffusely reflected light component determination against the known standard and was measured at $60^{\circ}$ angle. The measurements and determination were conducted by using the standard ISO 8254 method and ten measurements on each sample has been made.

b) Abrasion resistance

The abrasion resistance of all samples-printed papers were made on rub tester Labthink (China), according to TAPPI T830 standard. The test was proceeded on dry samples and two of each paper samples were tested. The procedure was carried out on dual stations with arc movement. In our research two stroke (Rubbing Times) were determined: 25 and 50 cycles, at rubbing speed $106 \mathrm{cpm}$ and rub pressure $8.9 \mathrm{~N}$. For determination of print abrasion, optical density was measured before and after rubbing.

\subsubsection{Thermal aging of papers}

The accelerated thermal ageing of the investigated paper samples was conducted according to ISO 56301:2014 in closed chamber at $105{ }^{\circ} \mathrm{C}$ and air circulation for standard humidity of $50 \%$ with duration of 
72 hours, because from the literature review is known that $72 \mathrm{~h}$ of thermal ageing corresponds to 25 years of natural ageing of paper.

For measuring the optical properties of the paper samples - whiteness CIE, whiteness CIE - UV, ISO brightness, ISO brightness - UV, fluorescense CIE, fluorescense ISO brightness (ISO 2470: 2016) was used Konica Minolta spectrophotometer.

\section{RESULTS AND DISCUSSION}

\subsection{Basic properties of papers and films}

To evaluate the influence and effect of bio based components onto paper, it was essential to establish and make samples with the same grammage. Therefore, the paper sheets were prepared with the grammage $80 \mathrm{~g} / \mathrm{m}^{2}$. The beating degree of a pulp, hardwood fibres, dimensions of the fibres and addition of the fillers have influence on thickness of the paper. This plays an important role at end usage, especially at printing papers. As expected, the thickness of the samples had mostly the same values (Table 1). Paper with only pulp, combination of softwood and hardwood fibres with no additives, had the lowest thickness $(0.0084 \mathrm{~mm})$. With addition of the retention additive and fillers, the thickness at all other paper sheets increased respectively. The changes were also detected at specific surface and density, where sample $\mathrm{P}$, with only pulp and no additives, had the highest density, compared to other tested papers.

Table 1: Basic properties (grammage, thickness, specific surface and density) of all paper samples

\begin{tabular}{|l|c|c|c|c|c|c|}
\hline \multirow{2}{*}{ Anlysis } & \multicolumn{6}{|c|}{ Samples } \\
\cline { 2 - 7 } & $\mathrm{P}$ & $\mathrm{PR}$ & $5 \% \mathrm{CH}$ & $5 \% \mathrm{CHR}$ & $7.5 \% \mathrm{CH}$ & $7.5 \mathrm{CHR}$ \\
\hline $\begin{array}{l}\text { Grammage } \\
\left(\mathrm{g} / \mathrm{m}^{2}\right)\end{array}$ & 80 & 80 & 80 & 80 & 80 & 80 \\
\hline $\begin{array}{l}\text { Thickness } \\
(\mathrm{mm})\end{array}$ & 0.084 & 0.095 & 0.091 & 0.090 & 0.095 & 0.096 \\
\hline $\begin{array}{l}\text { Specific } \\
\text { surface } \\
\left(\mathrm{m}^{3} / \mathrm{g}\right)\end{array}$ & 0.0011 & 0.0012 & 0.0011 & 0.0011 & 0.0012 & 0.0012 \\
\hline $\begin{array}{l}\text { Density } \\
\left(\mathrm{g} / \mathrm{m}^{3}\right)\end{array}$ & 952.38 & 842.11 & 879.12 & 888.89 & 842.11 & 833.33 \\
\hline
\end{tabular}

In this study, an ultrasonic treatment of the film solution was used in order to increase the solubility of composition components, which influenced many film properties (strength, elongation, moisture and colour). Generally, colour is an important factor of the appearance of packaging materials. The total colour difference, chroma and hue angle were calculated from the colour values. The untreated chitosan films were more coloured than rice starch and blend films. It is known that chitosan has more yellowness compared to other tested samples in the research. From the $L^{*}$ values, which indicate lightness, it can be seen that the treated samples became less coloured, are lighter, especially the rice starch film. The a* and $b^{*}$ values vary significantly between the untreated and treated samples. All films include a plasticiser, which also affected the colour. The hue angle was not significantly different among all sample films. The results of calculated chroma showed that the untreated samples have more yellowness than the treated ones.

Table 2: Thickness and colour values of the sample films

\begin{tabular}{|l|l|c|c|c|c|c|c|c|}
\cline { 2 - 8 } \multicolumn{1}{c|}{} & Sample & $\begin{array}{c}\text { Thickness } \\
(\mu \mathrm{m})\end{array}$ & $\mathrm{L}^{*}$ & $\mathrm{a}^{*}$ & $\mathrm{~b}^{*}$ & $\Delta \mathrm{E}$ & $\mathrm{C}$ & $\mathrm{H}$ \\
\hline \multirow{3}{*}{ Untreated } & Chitosan film & 210 & 84.06 & -3.19 & 10.36 & 3.56 & 10.84 & 178.75 \\
\cline { 2 - 9 } & Rice starch film & 205 & 86.65 & -4.07 & 9.88 & 6.28 & 10.67 & 178.89 \\
\cline { 2 - 9 } & Blend film & 215 & 88.92 & -3.00 & 11.35 & 5.92 & 11.73 & 178.75 \\
\hline \multirow{2}{*}{$\begin{array}{l}\text { Treated with } \\
\text { ultrasound }\end{array}$} & Chitosan film & 207 & 85.78 & -2.05 & 9.22 & 2.36 & 9.45 & 178.68 \\
\cline { 2 - 9 } & Rice starch film & 203 & 91.66 & -4.89 & 7.30 & 5.69 & 8.79 & 179.21 \\
\cline { 2 - 9 } & Blend film & 216 & 90.45 & -2.78 & 9.07 & 5.50 & 9.49 & 178.75 \\
\hline
\end{tabular}




\subsection{Smoothness and air permeability of papers}

Paper is a highly porous material consisting of a matted fibre layer, and the additives could cause the variation of many properties such as smoothness and air permeability. The open surface of paper sheets decreased with increasing amounts of the above-mentioned polymers. Smoothness was better in samples with chitosan and rice starch. The smoothness also improved with increasing amounts of bio-polymers. As expected and shown in Figure 1, the air permeability was worst for paper containing only pulp. With the addition of bio-polymers and retention additive, the structure of the paper became more uniform and filled, improving the properties. The best air permeability was achieved by paper with $7.5 \% \mathrm{KHR}$, where only $1186 \mathrm{mml} / \mathrm{min}$ was measured.

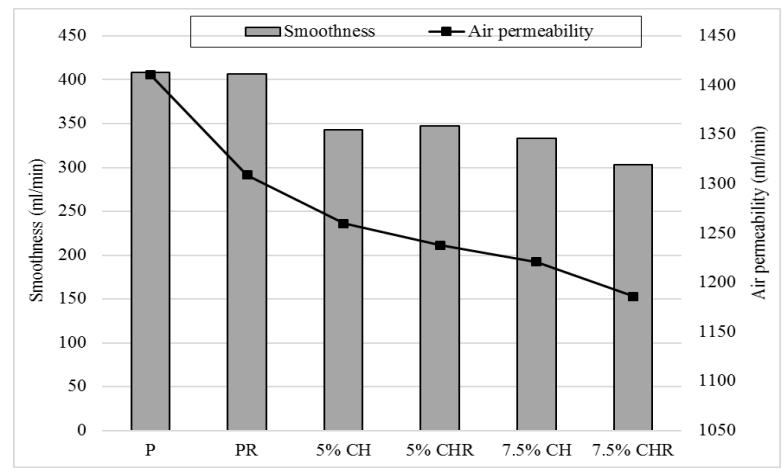

Figure 1: Smoothness and air permeability

\subsection{SEM of papers and films}

With scanning electron microscope (SEM) the evaluation of the distribution of chitosan and rice starch onto the paper sheets has been evaluated.

These micrographs (Figure 2) show that the fillers covered the fibres and closed the pores and open areas in the base paper. The surface of the sample papers showed a smoother and more uniform surface for papers with fillers (Figure 7-5\% CH, 5\% CHR, 7.5\% CH and 7.5\% CHR) compared to the samples without fillers (P and PR).

A comparison between paper sheets with used fillers but different concentrations proved their effect, which is consistent with improved mechanical, grease and water barrier properties. The absorption, thickness, moisture and roughness of the papers with fillers have a great influence on the properties of the chemical structures, types of fillers. If the fillers are unevenly distributed in the fibre paper composition, many properties can deteriorate afterwards and this can also influence the printing process (uneven printing image and mottling).
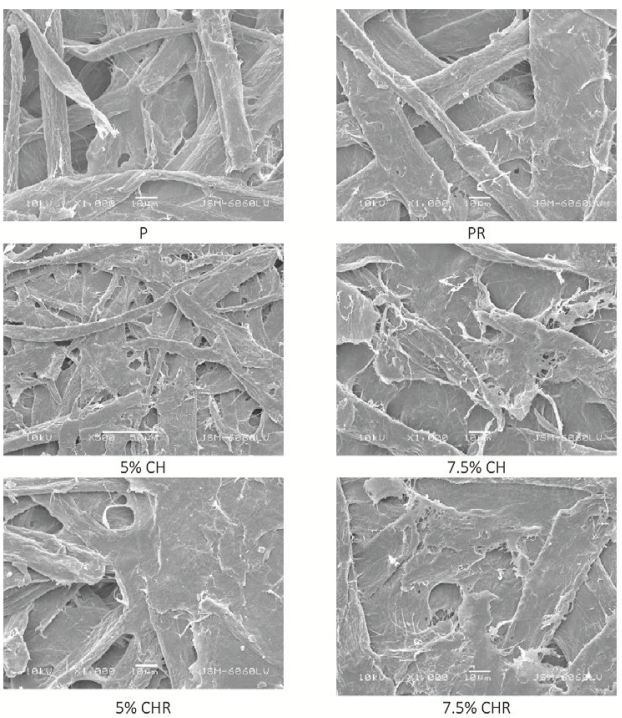

Figure 2: SEM micrographs of all samples taken at 1000x magnification and operating at 10kV voltage 
The surface micrographs showed a smoother, more even surface on all treated films. As can be seen in Figure $3 a$, the untreated chitosan film is less smooth and not as uniform as the ultrasonically treated film (Figure $3 b$ ). The same trend can be seen in Figures $3 c$ and $3 d$, where the SEM micrographs of rice starch are shown. Figure $3 c$ shows that the untreated rice starch film has a more irregular surface than the chitosan film. The untreated chitosan rice starch film had a less uniform, smooth and dense structure (Figures $3 e$ and $3 f$ ). The ultrasonic treatment caused a homogeneity of the surface and is a good indicator for better structural and mechanical properties compared to the untreated film. In general, the ultrasonic treatment helps to obtain a smoother and more homogeneous surface.

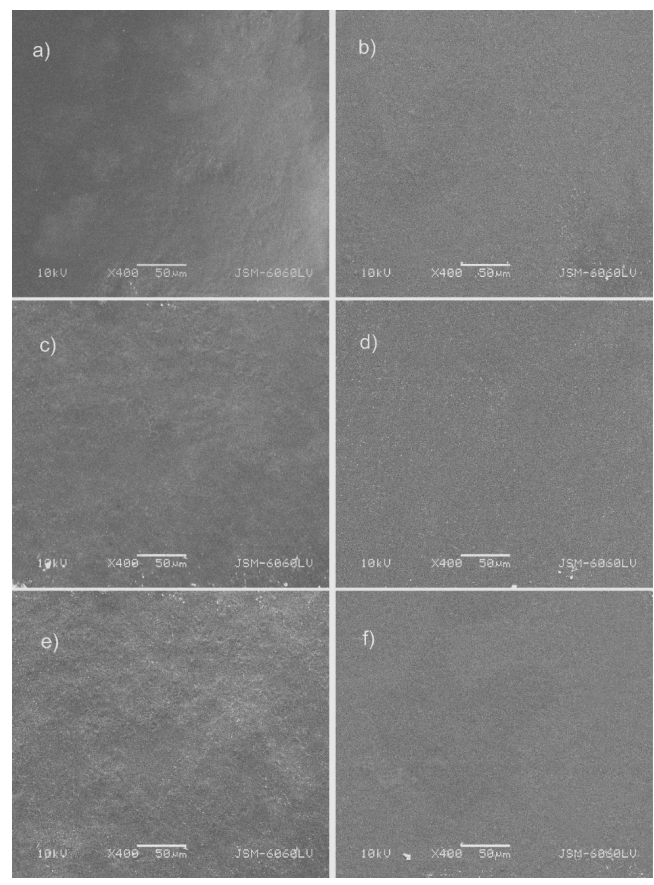

Figure 3: SEM micrographs of untreated and ultrasound treated films: a) untreated chitosan film, b) treated chitosan film, (c) untreated rice starch film, d) treated rice starch film, e) untreated blend chitosan-rice starch film, f) treated blend chitosan-rice starch film

\subsection{Printing quality of papers}

With papers, colour is important for future finishing and printing processes. It determines the quality of the light reflected by the paper, which is described by hue, saturation and darkness or lightness. The base paper determines the optical properties, whereby the brightness should be as close as possible to the brightness of the sample paper. In the investigation, the paper used was not bright white, it was slightly brown, and the fillers with chitosan did not have the same effect as on white paper. Chitosan powder is naturally yellowish, but rice starch is white, so the fillers on paper did not cause any major colour changes, as can be seen from Table 3. The colour difference was calculated from the results of the printed colours $(\Delta E)$.

Table 3: Colour values $\left(L^{*} a^{*} b^{*}\right)$, colour difference $(\Delta E)$ and gloss of all sample papers

\begin{tabular}{|c|c|c|c|c|c|}
\hline \multirow[b]{2}{*}{ Samples } & \multicolumn{3}{|c|}{ Colour values } & \multirow{2}{*}{$\begin{array}{l}\Delta \mathrm{E} \\
(/)\end{array}$} & \multirow{2}{*}{$\begin{array}{c}\text { Gloss at } 75^{\circ} \\
(/)\end{array}$} \\
\hline & $\mathrm{L}^{*}$ & $a^{*}$ & $b^{*}$ & & \\
\hline$P$ & -0.601 & 2.80 & 1.29 & / & 4.2 \\
\hline $\mathrm{PH}$ & -0.603 & 2.81 & 0.90 & 0.39 & 4.4 \\
\hline $5 \% \mathrm{CH}$ & -0.606 & 2.84 & 2.56 & 1.27 & 5.6 \\
\hline $5 \% \mathrm{CHR}$ & -0.605 & 2.82 & 2.15 & 0.86 & 5.3 \\
\hline $7.5 \% \mathrm{CH}$ & -0.605 & 2.84 & 3.18 & 1.89 & 5.8 \\
\hline $7.5 \%$ CHR & -0.605 & 2.82 & 2.84 & 1.55 & 5.6 \\
\hline
\end{tabular}


The colour difference was calculated according to the sample, including only pulp (P). As expected, the higher difference occurred in samples where chitosan and rice starch were added. For $5 \%$ chitosan and rice starch, the colour difference due to the addition of rice starch was less than for $5 \%$ chitosan. The same value was $7.5 \%$, with the largest colour difference calculated only for chitosan $(\Delta E=1.89)$, but in combination with rice starch it was smaller (1.55).

Colour is not one of the main properties of this packaging material, and this type of mixed filler does not have a significant effect on the printing properties, e.g. the colours, and could therefore be used in this area.

The gloss is related to the surface morphology and is achieved during drying. Due to the additives and fillers in the paper sheets it is known that they also improve the gloss values. The gloss of filled papers increased, even more so for papers where a higher proportion of fillers was used, especially with $7.5 \%$ chitosan (around 5.8). For low gloss papers, rice starch was added, but the difference is small. This is in line with the results of previous studies where fillers were reported to also improve surface smoothness, making the surface glossier after application.

Abrasion resistance was used to evaluate the resistance of printed surfaces to frictional abrasion. Failure or damage to paper is related to substrate ink adhesion, paper additives, thickness and internal stress. It should be noted that there are several methods that can characterise other aspects of imaging material degradation as a result of frictional contact with different surfaces under different conditions. Therefore, the application of specific methods depends on the end-user applications, such as the type of packaging materials and coatings, barrier properties requirements of the packaging paper, etc. In our study, the TAPPI standard was used as the standard method for determining the print quality of reamed sample papers.

In our research, dry friction test and two-cycle (Rubbing Times) were determined: 25 and 50 cycles, at a friction speed of $106 \mathrm{cpm}$. As shown in Figure 4, the dry rubbing test showed that all paper samples with bio-polymers gave better results (optical density) compared to paper with pulp and retention additive only.

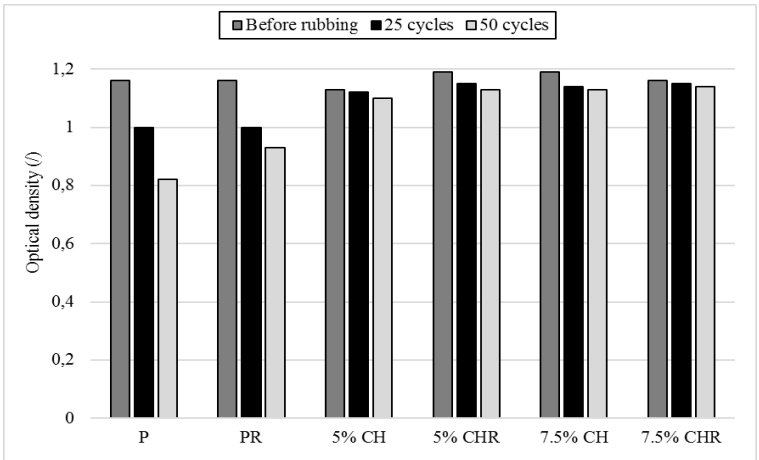

Figure 4: Optical density of all paper samples before and after rubbing 25 and 50 cycles

After 25 cycles (Figure 4) papers, where chitosan and/or rice starch was included, achieved better quality, according to other papers. Before rubbing, the highest optical density (1.19) had papers with $5 \%$ chitosan and $7.5 \%$ of chitosan and rice starch. At paper, where the highest amount of fillers was used (7.5\%) the smallest decrease after rubbing (25 and 50 cycles) of optical density was detected. Paper, where only chitosan was used, the optical density after rubbing, was almost the same as at paper with added rice starch. The highest the concentration of the fillers was, the most stable colour resistance was after rubbing 50 cycles. As expected, fillers increased colour stability, compared to paper sheet, where the fillers were not used. From this part is can be concluded that rice starch and chitosan had great influence on more stable and durable printing properties.

\subsection{Thermal aging of papers}

Table 3 shows the results for the optical properties of the investigated paper samples with and without addition of different amount of chitosan and hitosan and rice starch blends.

The results for the Whiteness CIE, Whiteness CIE - UV, ISO Brightness, ISO Brightness - UV, Fluorescense $\mathrm{CIE}$ and Fluoresense ISO Brightness shows that paper samples with only pulp (P) have the highest optical properties, followed by the samples from pulp and retention additive (PR). Adding the blends in the 
cellulose suspension in different ratios cause yellowing of the paper colour, visible to the human eye. But the differences between the Whiteness CIE, Whiteness CIE - UV, ISO Brightness, ISO Brightness - UV of the paper samples with $5 \%$ and $7,5 \%$ bled fillers are insignificant to the human eye, which the spectrophotometer shows by a difference in the range of 1-2 units.

Table 3: Optical properties of paper samples during 72 hours of accelerated thermal ageing

\begin{tabular}{|c|c|c|c|c|c|}
\hline \multirow[t]{2}{*}{$\begin{array}{l}\text { Optical } \\
\text { parameter }\end{array}$} & \multirow[t]{2}{*}{$\begin{array}{l}\text { Paper } \\
\text { samples }\end{array}$} & \multicolumn{4}{|c|}{ Hours of thermal ageing } \\
\hline & & 0 & 24 & 48 & 72 \\
\hline \multirow[t]{6}{*}{ Whiteness CIE } & $P$ & 52,74 & 39,71 & 31,27 & 24,86 \\
\hline & $P R$ & 45,99 & 32,96 & 25,2 & 19,9 \\
\hline & $5 \% \mathrm{CH}$ & 29,65 & 9,9 & $-1,41$ & $-9,99$ \\
\hline & $5 \% \mathrm{CHR}$ & 34,26 & 14,42 & 2,95 & $-5,21$ \\
\hline & $7,5 \% \mathrm{CH}$ & 35,86 & 16,9 & 5,75 & $-2,17$ \\
\hline & $7,5 \% \mathrm{CHR}$ & 34,55 & 13,65 & 1,38 & $-7,4$ \\
\hline \multirow{6}{*}{$\begin{array}{c}\text { Whiteness CIE } \\
- \text { UV }\end{array}$} & $P$ & 52,48 & 39,47 & 30,98 & 24,53 \\
\hline & PR & 45,85 & 32,74 & 24,97 & 19,6 \\
\hline & $5 \% \mathrm{CH}$ & 29,58 & 9,9 & $-1,32$ & $-10,03$ \\
\hline & $5 \% \mathrm{CHR}$ & 34,17 & 14,34 & 2,92 & $-5,33$ \\
\hline & $7,5 \% \mathrm{CH}$ & 35,8 & 16,9 & 5,75 & $-2,26$ \\
\hline & $7,5 \% \mathrm{CHR}$ & 34,46 & 13,67 & 1,41 & $-7,5$ \\
\hline \multirow{6}{*}{$\begin{array}{c}\text { ISO } \\
\text { Brightness }\end{array}$} & $P$ & 75,85 & 71,25 & 68,09 & 65,94 \\
\hline & $P R$ & 72,78 & 68,1 & 65,13 & 63,28 \\
\hline & $5 \% \mathrm{CH}$ & 67,82 & 61,38 & 57,56 & 54,87 \\
\hline & $5 \% \mathrm{CHR}$ & 69,48 & 62,93 & 59,03 & 56,43 \\
\hline & $7,5 \% \mathrm{CH}$ & 70,18 & 63,79 & 59,95 & 57,42 \\
\hline & $7,5 \% \mathrm{CHR}$ & 70,27 & 63,5 & 59,33 & 56,6 \\
\hline \multirow{6}{*}{$\begin{array}{c}\text { ISO } \\
\text { Brightness - } \\
\text { UV }\end{array}$} & $P$ & 75,84 & 71,21 & 68,04 & 65,9 \\
\hline & $P R$ & 72,75 & 68,08 & 65,09 & 63,23 \\
\hline & $5 \% \mathrm{CH}$ & 67,82 & 61,38 & 57,57 & 54,85 \\
\hline & $5 \% \mathrm{CHR}$ & 69,48 & 62,9 & 59,02 & 56,42 \\
\hline & $7,5 \% \mathrm{CH}$ & 70,18 & 63,78 & 59,94 & 57,4 \\
\hline & $7,5 \% \mathrm{CHR}$ & 70,27 & 63,49 & 59,34 & 56,56 \\
\hline \multirow{6}{*}{$\begin{array}{c}\text { Fluorescence } \\
\text { CIE }\end{array}$} & $P$ & 0,26 & 0,24 & 0,29 & 0,33 \\
\hline & PR & 0,14 & 0,21 & 0,23 & 0,3 \\
\hline & $5 \% \mathrm{CH}$ & 0,07 & 0 & $-0,1$ & 0,04 \\
\hline & $5 \% \mathrm{CHR}$ & 0,09 & 0,08 & 0,03 & 0,12 \\
\hline & $7,5 \% \mathrm{CH}$ & 0,06 & 0,01 & 0,01 & 0,1 \\
\hline & $7,5 \%$ CHR & 0,09 & $-0,02$ & $-0,03$ & 0,09 \\
\hline \multirow{6}{*}{$\begin{array}{c}\text { Fluorescence } \\
\text { ISO } \\
\text { Brightness }\end{array}$} & $P$ & 0,01 & 0,04 & 0,05 & 0,04 \\
\hline & $P R$ & 0,02 & 0,02 & 0,04 & 0,05 \\
\hline & $5 \% \mathrm{CH}$ & 0 & 0 & $-0,01$ & 0,01 \\
\hline & $5 \% \mathrm{CHR}$ & 0,01 & 0,03 & 0,01 & 0,01 \\
\hline & $7,5 \% \mathrm{CH}$ & $-0,01$ & 0,01 & 0 & 0,02 \\
\hline & $7,5 \%$ CHR & 0 & 0 & $-0,01$ & 0,03 \\
\hline
\end{tabular}


The investigation on the optical properties of the obtained paper samples during accelerated thermal shows that the ageing of paper with addition of chitosan and chitosan and rice starch blends have the same behaviour through the 72 hours of ageing. The largest change is observed in the first studied parameter - Whiteness CIE (Figure 5), which after the end of the accelerated thermal aging has decreased by approximately $50 \%$.

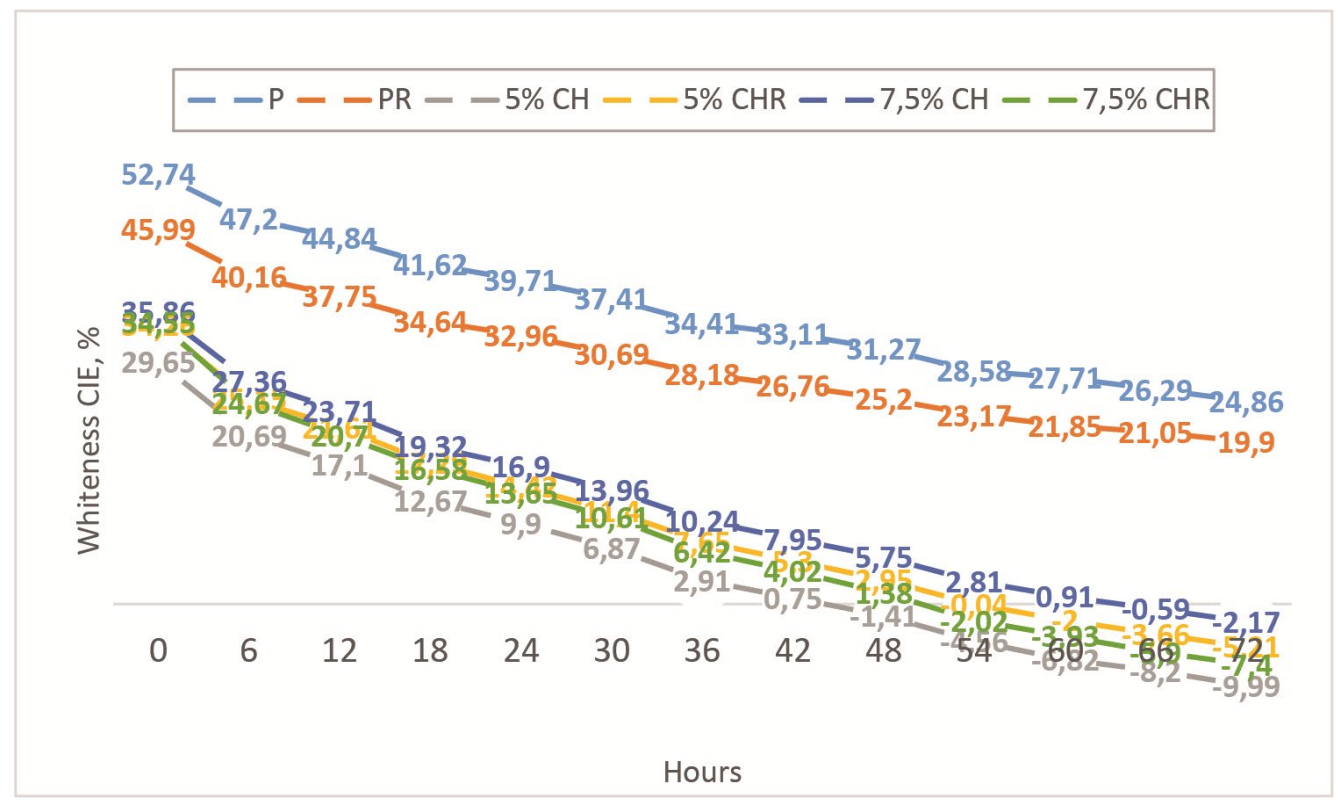

Figure 5: Whiteness CIE, \% of the tested paper samples during thermal aging

For the second parameter ISO Brightness (Figure 6) the decrease is in the range of 10 units, and again the nature of the change during ageing for all paper samples is similar.

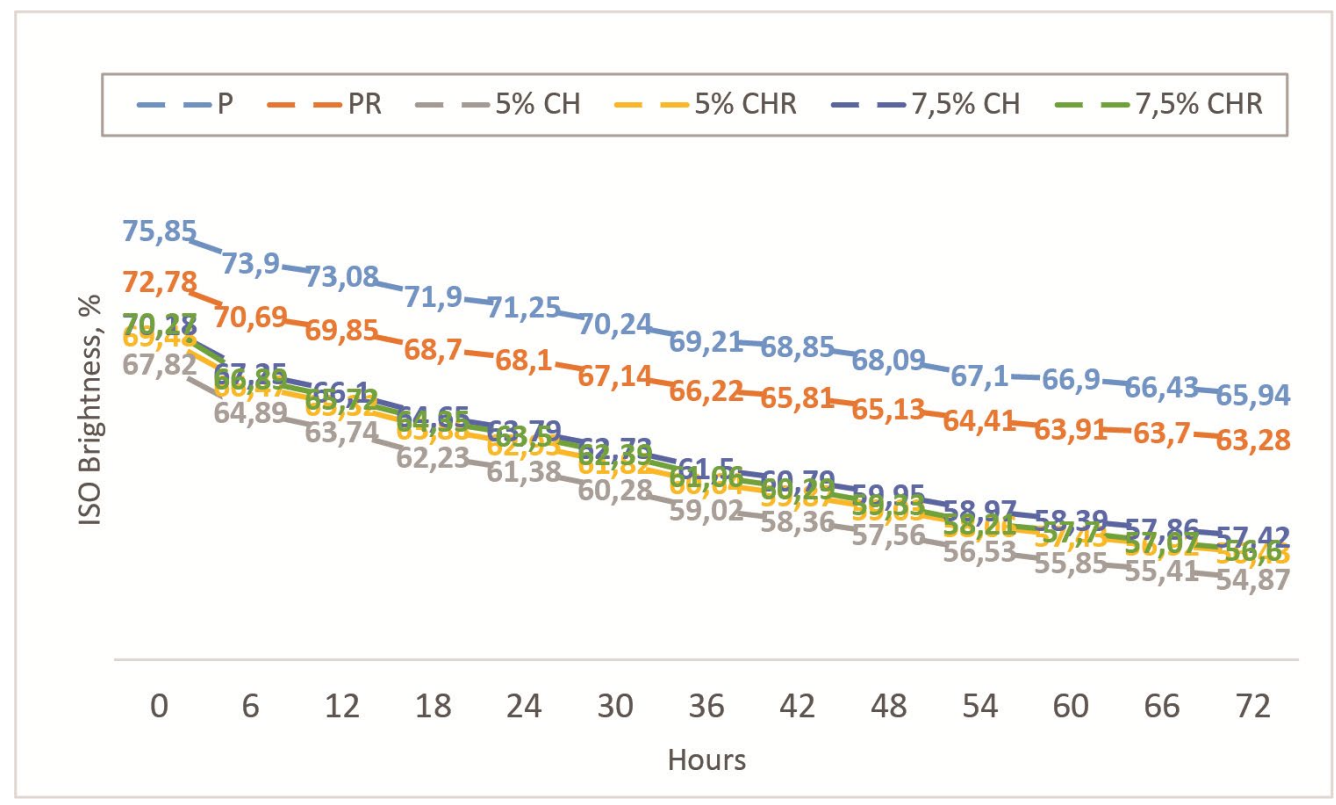

Figure 6: ISO brightness, \% of the tested paper samples during thermal aging

Large fluctuations are observed for the third examined parameter - Fluorescence CIE (Figure 7), which may be due to the low values of this indicator and the accuracy range of the used measuring device. All three graphs show that paper samples with $7.5 \%$ chitosan $(7.5 \% \mathrm{CH})$ has the closest optical properties to the zero paper sample. 


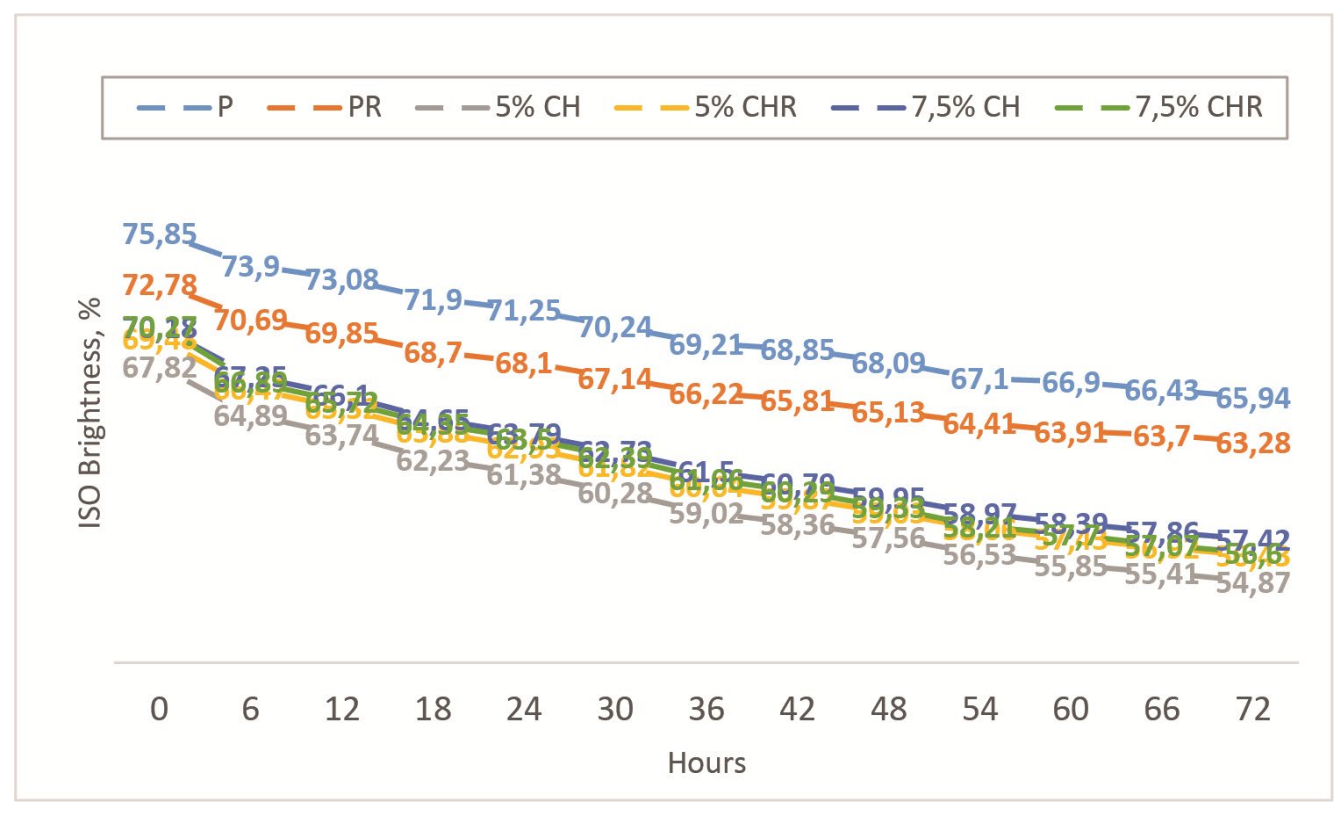

Figure 7: Fluorescence CIE, \% of the tested paper samples during thermal aging

\section{CONCLUSIONS}

Certain fillers in the paper can make their functionality and the end use of the paper possible. From previous and our research, it has been proven that the fillers can offer many advantages, such as improved printing, surface and many barrier properties. For packaging paper, print quality is an important factor among other properties. Research has shown that paper samples with bio-based fillers improved abrasion resistance and at the same time, no major colour differences occurred compared to paper without fillers. The ageing of paper with the addition of chitosan and chitosan and rice starch blends has shown that they show the same behaviour over the 72 hours of ageing. Further, to improve the barrier properties of packaging paper, this type of bio-based paper could be associated with additional additives and concentrations of polymers and additives presented in our study.

\section{REFERENCES}

[1] Aghazadeh, M., Karim, R., Sultan, M. T., Paykary, M., Johnson, S. K., Shekarforoush, E.: "Comparison of starch films and effect of different rice starch-based coating formulations on physical properties of walnut during storage time at accelerated temperature", Journal of Food Processing Engineering 41, e12607, 2018. doi: 10.1111/jfpe.12607

[2] Amirabad, L. M., Jonoobi, M., Mousavi, N. S., Oksman, K., Kaboorani, A., Yousefi, H.: "Improved antifungal activity and stability of chitosan nanofibers using cellulose nanocrystal on banknote papers", Carbohydrate Polymers 189, 229-237, 2018. doi: 10.1016/j.carbpol.2018.02.041

[3] Ashwar, B. A., Shah, A., Gani, A., Shah, U., Gani, A., Wani, I.A., Masoodi, F. A.: "Rice starch active packaging films loaded with antioxidants-development and characterization", Starch-Stärke 67, 294-302, 2015. doi: 10.1002/star.201400193

[4] Bourtoom, T., Chinnan, M. S.: "Preparation and properties of rice starch - chitosan blend film", Food Science and Technology 41, 1633-1641, 2008. doi: 10.1016/j.Iwt.2007.10.014

[5] Bourtoom, T., Chinnan, M. S.: "Improvement of water barrier property of rice starch-chitosan composite film incorporated with lipids", Food Science and Technology International 15, 149-158, 2009. doi: 10.1177/1082013208105993

[6] Brodnjak, U. V., Todorova, D.: "Novel Packaging Paper Made from Blend Fillers of Chitosan and Rice Starch", Journal of Polymer and Textile Engineering, 33-43, 2017. doi: 10.9790/019X-04033343

[7] Flores-Hernández, C. G., Colin-Cruz, A., Velasco-Santos, C., Castaño, V. M., Almendarez-Camarillo, A., Olivas-Armendariz, I., Martínez-Hernández, A. L.: "Chitosan-starch-keratin composites: improving thermo-mechanical and degradation properties through chemical modification", Journal of Polymer Environment 26, 2182-2191, 2018. doi: 10.1007/s10924-017-1115-1 
[8] Hoyos-Leyva, J. D., Bello-Pérez, L. A., Alvarez-Ramirez, J., Garcia, H. S.: "Microencapsulation using starch as wall material: A review", Food Review International 34, 148-161, 2018. doi: 10.1080/87559129.2016.1261298

[9] Iolovich, M.: "Isophase Transitions of Cellulose - A Short Review", Athens Journal of Sciences 3, 309 322, 2016. doi: 10.30958/ajs.3-4-4

[10] Jung, J., Raghavendra, G. M., Kim, D., Seo, J.: "One-step synthesis of starch-silver nanoparticle solution and its application to antibacterial paper coating", International Journal of Biological Macromolecules 107, 2285-2290, 2018. doi: 10.1016/j.ijbiomac.2017.10.108

[11] Khalil, A. H. P. S., Saurabh C. K., Adnan, A. S., Fazita, M. N., Syakir, M. I., Davoudpour, Y., Dungani, R.: "A review on chitosan-cellulose blends and nanocellulose reinforced chitosan biocomposites: Properties and their applications", Carbohydrate Polymers 150, 216-226, 2016. doi: 10.1016/j.carbpol.2016.05.028

[12] Li, H., Meng, B., Mahurin, S.M., Chai, S. H., Nelson, K. M., Baker, D. C., Dai, S.: "Carbohydrate based hyper-crosslinked organic polymers with-OH functional groups for CO 2 separation", Journal of Materials Chemistry A 3, 20913-20918, 2015. doi: 10.1039/c5ta03213j

[13] Lindh, E. L., Bergenstråhle-Wohlert, M., Terenzi, C., Salmén, L., Furó, I.: "Non-exchanging hydroxyl groups on the surface of cellulose fibrils: the role of interaction with water", Carbohydrate Research 434, 136-142, 2016. doi: 10.1016/j.carres.2016.09.006

[14] López-Mata, M. A., Ruiz-Cruz, S., de Jesús Ornelas-Paz, J., Del Toro-Sánchez, C. L., Márquez-Ríos, E., Silva-Beltrán, N. P., Burruel-Ibarra, S. E.: "Mechanical, barrier and antioxidant properties of chitosan films incorporating cinnamaldehyde", Journal of Polymer Environment 26, 452-461, 2018.

[15] Maitra, J., Singh, N.: "Starch-Chitosan Blend Cross-Linked with Calcium Chloride", Advances in Polymer Sciences and Technology, 133-145, 2018. doi: 10.1007/978-981-13-2568-7_13

[16] Mathew, S., Snigdha, S., Mathew, J., Radhakrishnan, E. K.: "Poly (vinyl alcohol): Montmorillonite: Boiled rice water (starch) blend film reinforced with silver nanoparticles; characterization and antibacterial properties", Applied Clay Science 161, 464-473, 2018. doi: 10.1016/j.clay.2018.05.009

[17] Mendes, J. F., Paschoalin, R. T-, Carmona, V. B., Neto, A. R. S., Marques, A. C. P., Marconcini, J. M., Oliveira, J. E.: "Biodegradable polymer blends based on corn starch and thermoplastic chitosan processed by extrusion", Carbohydrate Polymers 137, 452-458, 2016. doi: 10.1016/j.carbpol.2015.10.093

[18] Ogunsona, E., Ojogbo, E., Mekonnen, T.: "Advanced material applications of starch and its derivatives", European Polymer Journal 108, 570-581, 2018. doi: 10.1016/j.eurpolymj.2018.09.039

[19] Phan, D. N., Lee, H., Huang, B., Mukai, Y., Kim, I. S.: "Fabrication of electrospun chitosan/cellulose nanofibers having adsorption property with enhanced mechanical property", Cellulose 26, 17811793, 2019.

[20] Puvvada, Y. S., Vankayalapati, S., Sukhavasi, S.: "Extraction of chitin from chitosan from exoskeleton of shrimp for application in the pharmaceutical industry", International Current Pharmaceutical Journal 1, 258-263, 2012. doi: 10.3329/icpj.v1i9.11616

[21] Romani, V. P., Prentice-Hernández. C., Martins. V. G.: "Active and sustainable materials from rice starch, fish protein and oregano essential oil for food packaging", Industrial Crop and Products 97, 268-274, 2017. doi: 10.1016/j.indcrop.2016.12.026

[22] Sabbah, M., Di Pierro, P., Dell'Olmo, E., Arciello, A., Porta, R.: "Improved shelf-life of Nabulsi cheese wrapped with hydrocolloid films", Food Hydrocolloids 96, 29-35, 2019. doi: 10.1016/j.foodhyd.2019.05.010

[23] Shah, U., Naqash, F., Gani A., Masoodi, F. A.: "Art and science behind modified starch edible films and coatings: a review", Comprehensive Reviews in Food Science and Food safety 15, 568-580, 2016. doi: 10.1111/1541-4337.12197

[24] Tang, Y., Hu, X., Zhang, X., Guo, D., Zhang, J., Kong, F.: "Chitosan/titanium dioxide nanocomposite coatings: Rheological behavior and surface application to cellulosic paper", Carbohydrate Polymers 151, 752-759, 2016. doi: 10.1016/j.carbpol.2016.06.023

[25] Ten, E., Vermerris, W.: "Functionalized polymers from lignocellulosic biomass: State of the art", Polymers 5, 600-642, 2013. doi: 10.3390/polym5020600

[26] Thakur, R., Saberi, B., Pristijono, P., Golding, J., Stathopoulos, C., Scarlett, C., Vuong, Q.: "Characterization of rice starch-ı-carrageenan biodegradable edible film. Effect of stearic acid on the film properties", International Journal of Biological Macromolecules 93, 952-960, 2016. doi: 10.1016/j.jibiomac.2016.09.053 
[27] Vrabič Brodnjak, U.: "Infuence of ultrasonic treatment on properties of bio-based coated paper", Progress in organic coatings 103, 93-100, 2017. doi: 10.1016/j.porgcoat.2016.10.023

[28] Woggum, T., Sirivongpaisal, P., Wittaya, T. "Characteristics and properties of hydroxypropylated rice starch based biodegradable films", Food Hydrocolloids 50, 54-64, 2015. doi: 10.1016/j.foodhyd.2015.04.010

[29] Zarayneh, S., Sepahi, A. A., Jonoobi, M., Rasouli, H.: "Comparative antibacterial effects of cellulose nanofiber, chitosan nanofiber, chitosan/cellulose combination and chitosan alone against bacterial contamination of Iranian banknotes", International Journal of Biological Macromolecules 118, 10451054, 2018. doi: 10.1016/j.ijbiomac.2018.06.160

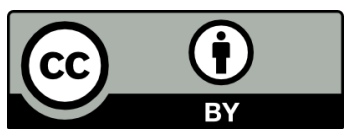

(C) 2020 Authors. Published by the University of Novi Sad, Faculty of Technical Sciences, Department of Graphic Engineering and Design. This article is an open access article distributed under the terms and conditions of the Creative Commons Attribution license 3.0 Serbia (http://creativecommons.org/licenses/by/3.0/rs/). 